\title{
Cross-feeding between Bifidobacterium infantis and Anaerostipes caccae on lactose and human milk oligosaccharides
}

\author{
L.W. Chia ${ }^{1}$, M. Mank ${ }^{2}$, B. Blijenberg ${ }^{2}$, R.S. Bongers ${ }^{2}$, K. van Limpt ${ }^{2}$, H. Wopereis ${ }^{2}$, S. Tims ${ }^{2}$, B. Stahl ${ }^{2,3}$, C. Belzer $^{*}$ \\ and $\mathrm{J}$. Knol ${ }^{1,2}$ \\ ${ }^{1}$ Laboratory of Microbiology, Wageningen University and Research, Stippeneng 4, 6708 WE, Wageningen, the Netherlands; \\ ${ }^{2}$ Nutricia Research, Uppsalalaan 12, 3584 CT, Utrecht, the Netherlands; ${ }^{3}$ Department of Chemical Biology E Drug Discovery, \\ Utrecht Institute for Pharmaceutical Sciences, Utrecht University, Universiteitsweg 99, 3584 CG, Utrecht, the Netherlands; \\ clara.belzer@wur.nl
}

Received: 12 January 2020 / Accepted: 2 July 2020

(c) 2020 Wageningen Academic Publishers

OPEN ACCESS @(1)(0) RESEARCH ARTICLE

\begin{abstract}
The establishment of the gut microbiota immediately after birth is a dynamic process that may impact lifelong health. At this important developmental stage in early life, human milk oligosaccharides (HMOs) serve as specific substrates to shape the gut microbiota of the nursling. The well-orchestrated transition is important as an aberrant microbial composition and bacterial-derived metabolites are associated with colicky symptoms and atopic diseases in infants. Here, we study the trophic interactions between an HMO-degrader, Bifidobacterium infantis and the butyrogenic Anaerostipes caccae using carbohydrate substrates that are relevant in the early life period including lactose and total human milk carbohydrates. Mono- and co-cultures of these bacterial species were grown at pH 6.5 in anaerobic bioreactors supplemented with lactose or total human milk carbohydrates. A. caccae was not able to grow on these substrates except when grown in co-culture with $B$. infantis, leading to growth and concomitant butyrate production. Two levels of cross-feeding were observed, in which $A$. caccae utilised the liberated monosaccharides as well as lactate and acetate produced by $B$. infantis. This microbial cross-feeding points towards the key ecological role of bifidobacteria in providing substrates for other important species that will colonise the infant gut. The progressive shift of the gut microbiota composition that contributes to the gradual production of butyrate could be important for host-microbial crosstalk and gut maturation.
\end{abstract}

Keywords: bifidobacteria, butyrate, Lachnospiraceae, microbiome, $\mathrm{pH}$

\section{Introduction}

The succession of microbial species in the infant gut microbiota is a profound process in early life (Backhed et al., 2015; Koenig et al., 2011), which coincides with the important development of the immune, metabolic and neurological systems (Arrieta et al., 2014; Sherman et al., 2015; Thompson, 2012). At this developmental stage, human milk is recognised as the best nourishment for infants (Neville et al., 2012). Human milk contains a range of microbial active components and all human milk oligosaccharides (HMOs) play an important role in the development of the infant gut microbiota (Zivkovic et al., 2011). HMOs are complex carbohydrates composed of a lactose core, which may be elongated by $\mathrm{N}$-acetylglucosamine (GlcNAc), galactose and/or decorated with fucose and/or sialic acid (Smilowitz et al., 2014). The composition of HMOs in human milk is highly individual, driven by maternal genetic factors (Kunz et al., 2017; McGuire et al., 2017) and varies with the phases of lactation. The concentration of HMOs ranges from $23 \mathrm{~g} / \mathrm{l}$ in colostrum to $7 \mathrm{~g} / \mathrm{l}$ in matured human milk (Coppa et al., 1993; Gabrielli et al., 2011).

The majority of the HMOs escapes digestion by the host's enzymes in the upper gastrointestinal tract (Engfer et al., 2000). HMOs confer important physiological traits by acting both as a decoy for the binding of pathogenic 
bacteria and viruses, and as a prebiotic to stimulate the growth and activity of specific microbes in the infant gut (Bode, 2012). These complex carbohydrates exert a selective nutrient pressure to promote the HMO-utilising microbes, especially bifidobacteria belonging to the Actinobacteria phylum (Marcobal et al., 2010). Specifically, infantassociated bifidobacteria are well adapted to utilise HMOs by employing an extensive range of glycosyl hydrolases and transporters, which lead to their dominance in the infant gut ecosystem (Sela and Mills, 2010). Upon weaning, the relative abundance of bifidobacteria decreases with the increase of Firmicutes and Bacteroidetes phyla whilst the gut microbial diversity increases (Laursen et al., 2017).

The early dominance of bifidobacteria could be important for the maturation of the overall microbial community. In healthy children, the relative abundance of bifidobacteria is positively associated with the butyrate-producing Firmicutes from the family of Lachnospiraceae (also known as Clostridium cluster XIVa) and Ruminococcaceae (also known as Clostridium cluster IV) (Cheng et al., 2015). This butyrogenic community is often present at much lower relative abundance in the gut of new-borns (Jost et al., 2012). The subdominant butyrogenic species could however quickly become more dominant upon weaning as a result of the cessation of breast-feeding and the introduction of solid food (Backhed et al., 2015; Laursen et al., 2016). The expansion of the strict anaerobic, butyrateproducing bacteria could be a critical step for the gut and immune maturation (Arrieta et al., 2015; Wopereis et al., 2017). The interactions between lactate-producing bacteria (such as bifidobacteria) and lactate-utilising bacteria (such as Ruminococcaceae and Lachnospiraceae) are suggested to be associated with colicky symptoms and atopy disease in infants (Arrieta et al., 2015; De Weerth et al., 2013; Pham et al., 2017; Wopereis et al., 2017). To date, cross-feeding between glycan-degrading bifidobacteria and butyrateproducers using complex dietary carbohydrates (including starch, inulin, fructo-oligosaccharides, and arabinoxylan oligosaccharides) has been demonstrated in in vitro coculturing experiments (Belenguer et al., 2006; De Vuyst and Leroy, 2011; Falony et al., 2006; Rios-Covian et al., 2015; Riviere et al., 2015). However, limited studies have shown the cross-feeding between these groups of bacteria on host-secreted glycans, such as HMOs (Schwab et al., 2017) and mucins (Bunesova et al., 2017).

In this study, we elucidated the trophic interaction between a versatile HMO-utiliser, Bifidobacterium longum subsp. infantis (B. infantis) (Sela et al., 2008) and a butyrogenic non-degrader. To this end the butyrate-producer Anaerostipes caccae was selected as the representative species for the Lachnospiraceae family as it is detected in the early life gut microbiota (Backhed et al., 2015; Yatsunenko et al., 2012) with demonstrated in vitro crossfeeding interaction with adult-associated Bifidobacterium adolescentis (Belenguer et al., 2006). A. caccae is also recently identified as a key bacterium critical for regulating food allergy in early life (Feehley et al., 2019). We showed that $B$. infantis metabolises HMOs into monosaccharides and metabolites including lactate and acetate, to support the growth and concomitant butyrate production by A. caccae. This butyrogenic cross-feeding postulates the role of bifidobacteria in driving both the maturation of microbial ecology and physiology of infant gut.

\section{Materials and methods}

\section{Screening of 16S rRNA gene amplicon libraries}

16S rRNA gene amplicon sequencing datasets published by Yatsunenko et al. (2012) were downloaded from European Nucleotide Archive (PRJEB3079). The sequencing data of 529 faecal samples with known age of the sample donors was analysed using the Quantitative Insights Into Microbial Ecology (QIIME) release version 1.9.0 package (Caporaso et al., 2010). Sequences with mismatched primers, a mean sequence quality score $<15$ (five nucleotides window) or ambiguous bases were discarded. In total 1,036,929,139 sequences were retained with an average of 1,960,168.5 sequences per sample. The retained sequences were grouped into Operational Taxonomic Units with the USEARCH algorithm (Edgar, 2010) set at 97\% sequence identity and subsequently, the Ribosomal Database Project Classifier (Cole et al., 2009) was applied to assign taxonomy to the representative sequences by alignment to the SILVA ribosomal RNA database (release version 1.1.9) (Pruesse et al., 2007).

\section{Bacterial strains and growth conditions}

Bacterial pre-cultures were grown in anaerobic serum bottles filled with gas phase of $\mathrm{N}_{2} / \mathrm{CO}_{2}(80 / 20$ ratio) at $1.5 \mathrm{~atm}$. Pre-cultures were prepared by overnight $37^{\circ} \mathrm{C}$ incubation in basal minimal medium (Plugge, 2005) containing $0.5 \%(\mathrm{w} / \mathrm{v})$ tryptone (Oxoid, Basingstoke, UK), supplemented with $30 \mathrm{mM}$ lactose (Oxoid) for Bifidobacterium longum subsp. infantis ATCC15697; and $30 \mathrm{mM}$ glucose (Sigma-Aldrich, St. Louis, MO, USA) for Anaerostipes caccae L1-92 (DSM 14662) (Schwiertz et al. 2002). Growth was measured by a spectrophotometer at an optical density of $600 \mathrm{~nm}$ (OD600) (OD600 DiluPhotometer ${ }^{\mathrm{rnw}}$, IMPLEN, München, Germany).

\section{Carbohydrate substrates}

Lactose (Oxoid) and total human milk (HM) carbohydrates were tested as the carbohydrate substrates for bacterial growth. The usage and analysis of pooled HM samples described in this study were performed in accordance with ethical standards and guidelines as laid down in the Declaration of Helsinki. Ethical approval and written 
consents of donors were given as stated in the publications (Thurl et al., 1993). For preparation of total HM carbohydrates, a total carbohydrate mineral fraction was derived from pooled human milk after protein depletion by ethanol precipitation and removal of lipids by centrifugation as described by Stahl et al. (1994). Deviant from this workflow, no anion exchange chromatography was used to further separate neutral from acidic oligosaccharides present in the resulting total carbohydrate mineral fraction. The total HM carbohydrates contained approximately $90 \%$ of lactose, $10 \%$ of both acidic and neutral HMOs as well as traces of monosaccharides, as estimated by gel permeation chromatography (GPC) described below (Supplementary Figure S1).

\section{Anaerobic bioreactor}

Fermentations were conducted in eight parallel minispinner bioreactors (DASGIP, Jülich, Germany) with $100 \mathrm{ml}$ filling volume at $37^{\circ} \mathrm{C}$ and a stirring rate of $150 \mathrm{rpm}$. Culturing experiments were performed in autoclaved basal minimal media (Plugge, 2005) containing 0.5\% (w/v) tryptone (Oxoid), supplemented with $8 \mathrm{~g} / \mathrm{l}$ of $0.2 \mu \mathrm{M}$ filter-sterilised lactose or total HM carbohydrates. Anaerobic condition was achieved by overnight purging of anaerobic gas mixture containing $5 \% \mathrm{CO}_{2}, 5 \% \mathrm{H}_{2}$, and $90 \% \mathrm{~N}_{2}$. Overnight precultures were inoculated at starting OD600 of 0.05 for each bacterial strain. Online signals of $\mathrm{pH}$ values and oxygen levels were monitored by the DASGIP control software. Cultures were maintained at $\mathrm{pH} 6.5$ by the addition of $2 \mathrm{M} \mathrm{NaOH}$.

\section{Gel permeation chromatography}

Total HM carbohydrates were analysed using GPC. Glycans were separated by the GPC stationary phase and eluted according to size and charge. Neutral mono-, di-, and oligosaccharides, and acidic oligosaccharides with different degree of polymerisation (DP) could be detected. HM carbohydrate solution was prepared by dissolving $0.2 \mathrm{~g} / \mathrm{ml}$ of total HM carbohydrates in ultrapure water (Sartorius Arium Pro, Goettingen, Germany) containing $2 \%$ (v/v) 2-propanol at $37^{\circ} \mathrm{C} .5 \mathrm{ml}$ of $0.2 \mu \mathrm{M}$ filter-sterilised HM carbohydrate solution was injected for each GPC run. The sample loop was cleaned by ultrapure water prior to analysis. Two connected Kronlab ECO50 columns $(5 \times 110 \mathrm{~cm}$; YMC Europe, Dinslaken, Germany) packed with Toyopearl HW 40 (TOSOH Bioscience, Tokyo, Japan) were used. Milli-Q water was maintained at $50{ }^{\circ} \mathrm{C}$ using heating bath (Lauda, RE 206) for columns equilibration. Milli-Q (Milli-pore; Merck Millipore, Burlington, MA, USA) water containing $2 \%(\mathrm{v} / \mathrm{v})$ of 2-propanol was used as the eluent. The flow rate of the eluent was set at $1.65 \mathrm{ml} / \mathrm{min}$. Eluting glycans were monitored by refractive index detection (Shodex RI-101; Showa Denko America, Inc., New York, NY, USA). The resulting chromatograms were analysed by using the Chromeleon ${ }^{\oplus}$ software (v 6.80; ThermoFisher Scientific, Waltham, MA, USA).

\section{High-performance liquid chromatography}

For metabolite analysis, $1 \mathrm{ml}$ of bacterial culture was centrifuged, and the supernatant was stored at $-20{ }^{\circ} \mathrm{C}$ until high-performance liquid chromatography (HPLC) analysis. Crotonate was used as the internal standard, and external standards tested included lactose, glucose, galactose, $\mathrm{N}$-acetylglucosamine (GlcNAc), N-acetylgalactosamine (GalNAc), fucose, malate, fumarate, succinate, citrate, formate, acetate, butyrate, isobutyrate, lactate, 1,2-propanediol, and propionate. Substrate and metabolite were measured with a Spectrasystem HPLC (Thermo Scientific, Breda, the Netherlands) equipped with a HiPlex-H column (Agilent, Amstelveen, the Netherlands) for the separation of carbohydrates and organic acids. A Hi-Plex-H column performs separation with diluted sulphuric acid on the basis of ion-exchange ligand-exchange chromatography. Measurements were conducted at a column temperature of $45^{\circ} \mathrm{C}$ with an eluent flow of 0.8 $\mathrm{ml} / \mathrm{min}$ flow of $0.01 \mathrm{~N}$ sulphuric acid. Metabolites were detected by refractive index (Spectrasystem RI 150; Thermo Scientific).

\section{Human milk oligosaccharide extraction}

HMOs were recovered from $1 \mathrm{ml}$ aliquots of bacterial cultures. Internal standard 1,5- $\alpha$-L-arabinopentaose (Megazyme, Bray, Ireland) was added, at the volume of 10 $\mu \mathrm{l}$ per sample to minimise pipetting error, to reach a final concentration of $0.01 \mathrm{mmol} / \mathrm{l}$. The solution was diluted 1:1 with ultrapure water and centrifuged at $4,000 \times g$ for $15 \mathrm{~min}$ at $4{ }^{\circ} \mathrm{C}$. The supernatant was filtered through $0.2 \mu \mathrm{M}$ syringe filter followed by subsequent centrifugation with a prewashed ultra-filter (Amicon Ultra 0.5 Ultracel Membrane $3 \mathrm{kDa}$ device; Merck Millipore) at 14,000 $\times g$ for $1 \mathrm{~h}$ at room temperature. Finally, the filtrate was vortexed and stored at $-20{ }^{\circ} \mathrm{C}$ until further targeted liquid chromatography electrospray ionisation tandem mass spectrometry (LCESI-MS ${ }^{2}$ ) analysis.

\section{Targeted liquid chromatography electrospray ionisation tandem mass spectrometry analysis}

The identification and relative quantitation of HMOs were determined by LC-ESI-MS ${ }^{2}$ as described in Mank et al. (2019). This method allowed the study of distinct HMOs structures differing in monosaccharide sequence, glycosidic linkage or the molecular conformation. Thereby even the HMOs isobaric isomers such as lacto-N-fucopentaose (LNFP) I, II, III and V could be distinguished. LC-ESI-MS ${ }^{2}$ analysis was performed on a 1200/1260 series HPLC stack (Agilent, Waldbronn, Germany) consisting of solvent tray, degasser, binary pump, autosampler and DAD detector 
coupled to a 3200 Qtrap mass spectrometer (ABSciex, Framingham, MA, USA). After HMOs extraction (see above) $5 \mu \mathrm{l}$ of HMOs extract was injected into the LC-MS system. Oligosaccharides were separated by means of a $2.1 \times 30 \mathrm{~mm}$ Hypercarb porous graphitized carbon (PGC) column with $2.1 \times 10 \mathrm{~mm}$ PGC pre-column (ThermoFisher Scientific) using a 19 min water-ethanol (Merck, Darmstadt, Germany) gradient following 2 min pre-equilibrium according to Mank et al. (2019), with an additional $1 \mathrm{~min}$ for stabilisation at the end. Eluent flow was $400 \mu \mathrm{l} / \mathrm{min}$ and the columns were kept at $45^{\circ} \mathrm{C}$. The LC-effluent was infused online into the mass spectrometer and individual HMOs structures were analysed qualitatively and quantitatively by multiple reaction monitoring (MRM) in negative ion mode. Specific MRM transitions for neutral HMOs up to pentaoses and acidic HMOs up to trioses were included. The spray voltage was $-4,500 \mathrm{~V}$, declustering potential was at $44 \mathrm{~V}$, and collision energy was set to $29 \mathrm{eV}$. Each MRMtransition was performed for $50 \mathrm{~ms}$ (except for LNT and lactose for 25 and $10 \mathrm{~ms}$, respectively). The instrument was calibrated with polypropylene glycol according the instructions of the manufacturer. Unit resolution setting was used for precursor selection whereas low resolution setting was used to monitor fragment ions of the MRM transitions.

\section{Quantitative real-time PCR}

The abundance of $B$. infantis and A. caccae in mono- and co-culture were determined by quantitative real-time PCR. Bacterial cultures were harvested at $16,100 \times g$ for $10 \mathrm{~min}$. DNA extractions were performed using MasterPure ${ }^{\mathrm{mat}}$ Gram Positive DNA Purification Kit (Lucigen, Middleton, WI, USA). The DNA concentrations were determined fluorometrically (Qubit dsDNA HS assay; Invitrogen, Carlsbad, CA, USA) and adjusted to $1 \mathrm{ng} / \mu \mathrm{l}$ prior to use as the template in $\mathrm{qPCR}$. Primers targeting the 16S rRNA gene of Bifidobacterium spp. (F-bifido 5'-CGCGTCYGGTGTGAAAG-3'; R-bifido 5'-CCCCACATCCAGCATCCA-3'; 244 bp product (Delroisse et al., 2008)) and A. caccae (OFF2555 5'-GCGTAGGTGGCATGGTAAGT-3'; OFF2556 5'-CTGCACTCCAGCATGACAGT-3'; 83 bp product (Veiga et al., 2010)) were used for quantification. Standard template DNA was prepared by amplifying genomic DNA of each bacterium using primer pairs of 35F (5'-CCTGGCTCAGGATGAACG-3' (Hayashi et al., 2004)) and 1492R (5'-GGTTACCTTGTTACGACTT-3') for B. infantis; and 27F (5'-AGAGTTTGATCCTGGCTCAG-3') and 1492R for A. caccae. Standard curves were prepared with nine standard concentrations of $10^{0}$ to $10^{8}$ gene copies/ $\mu l$. PCRs were performed in triplicate with iQ SYBR Green Supermix (Bio-Rad, Hercules, CA, USA) in a total volume of $10 \mu \mathrm{l}$ with primers at $500 \mathrm{nM}$ in 384-well plates sealed with optical sealing tape. Amplification was performed with an iCycler (Bio-Rad) with the following protocol: $95^{\circ} \mathrm{C}$ for $10 \mathrm{~min}$; 40 cycles of $95^{\circ} \mathrm{C}$ for $15 \mathrm{~s}, 55^{\circ} \mathrm{C}$ for $20 \mathrm{~s}$, and $72^{\circ} \mathrm{C}$ for $30 \mathrm{~s} ; 95^{\circ} \mathrm{C}$ for $1 \mathrm{~min}$ and $60^{\circ} \mathrm{C}$ for $1 \mathrm{~min}$ followed by a stepwise temperature increase from 60 to $95^{\circ} \mathrm{C}\left(\right.$ at $0.5{ }^{\circ} \mathrm{C}$ per $5 \mathrm{~s}$ ) to obtain the melt curve data. Data was analysed using the Bio-Rad CFX Manager 3.0.

\section{Fluorescent in situ hybridisation}

Bacterial cultures were fixated by adding $1.5 \mathrm{ml}$ of $4 \%$ paraformaldehyde (PFA) to $0.5 \mathrm{ml}$ of cultures followed by storage at $-20{ }^{\circ} \mathrm{C}$. Noted that for optimum fixation, at least $2 \mathrm{~h}$ to overnight incubation at $4{ }^{\circ} \mathrm{C}$ is recommended. Working stocks were prepared by harvesting bacterial cells by centrifugation at $8,000 \times g$ for $5 \mathrm{~min}$ of $4{ }^{\circ} \mathrm{C}$, followed by re-suspension in ice-cold phosphate buffered saline (PBS) and $96 \%$ ethanol at a 1:1 (v/v) ratio. $3 \mu \mathrm{l}$ of the PBS-ethanol working stocks were spotted on 18 wells (round, $6 \mathrm{~mm}$ diameter) gelatine-coated microscope slides. Hybridisation was performed using rRNA-targeted oligonucleotide probes specific for Bifidobacterium genus (Bif164m 5'-CATCCGGYATTACCACCC-3' [5']Cy3) (Dinoto et al., 2006). $10 \mu \mathrm{l}$ of hybridisation mixture containing 1 volume of $10 \mu \mathrm{M}$ probe and 9 volumes of hybridisation buffer $(20 \mathrm{mM}$ Tris- $\mathrm{HCl}, 0.9 \mathrm{M} \mathrm{NaCl}, 0.1 \%$ sodium dodecyl sulphate, $\mathrm{pH}$ 7.2-7.4) was applied on each well. The slides were hybridised for at least $3 \mathrm{~h}$ in a moist chamber at $50^{\circ} \mathrm{C}$; followed by $30 \mathrm{~min}$ incubation in washing buffer $(20 \mathrm{mM}$ Tris- $\mathrm{HCl}, 0.9 \mathrm{M} \mathrm{NaCl}, \mathrm{pH} 7.2-7.4)$ at $50{ }^{\circ} \mathrm{C}$ for washing. The slides were rinsed briefly with Milli- $Q$ water and airdried. Slides were stained with 4,6-diamine-2-phenylindole dihydrochloride (DAPI) mix containing $200 \mu \mathrm{l}$ of PBS and $1 \mu \mathrm{l}$ of DAPI-dye at $100 \mathrm{ng} / \mu \mathrm{l}$, for $5 \mathrm{~min}$ in the dark at room temperature followed by Milli-Q rinsing and air-drying. The slides were then covered with Citifluor AF1 (Hatfield, PA, USA) and a coverslip. The slides were enumerated using an Olympus MT ARC/HG epifluorescence microscope (Olympus, Tokyo, Japan). A total of 25 positions per well were automatically captured in two colour channels (Cy3 and DAPI) using a quadruple band filter. Images were analysed using Olympus ScanR Analysis software.

\section{Carbohydrate-active enzymes prediction}

Carbohydrate-active enzymes (CAZymes) were predicted with dbCAN version 3.0 (Yin et al., 2012), transmembrane domains with TMHMM version 2.0c (Krogh et al., 2001) and signal peptides with signalP 4.1 (Petersen et al., 2011).

\section{Results}

\section{Occurrence of Bifidobacterium infantis and Anaerostipes caccae across the life span}

To understand the occurrence of $B$. infantis and A. caccae in the gut microbiota across life stages, a published dataset (Yatsunenko et al., 2012) was mined. The two infantassociated bacteria demonstrated opposite trajectories in 
early life. Bifidobacterium genus showed high abundance at the first year followed by a sharp decline, with a negative correlation between age and relative abundance (Spearman $\rho=-0.38, P<0.05$ ) (Figure 1), a similar finding as presented by Schwab et al. (2017). In contrast, Anaerostipes genus (Spearman $\rho=0.56, P<0.05$ ) and Lachnospiraceae family (Spearman $\rho=0.37, P<0.05$ ) were present at low abundance early in life and increased in relative abundance during the aging process (Figure 1).

\section{Model for Bifidobacterium infantis and Anaerostipes caccae co-occurrence}

Mono- and co-cultures of B. infantis and A. caccae were setup to study the metabolism and interaction between a versatile HMO-utiliser and a butyrate producer. Bacterial strains were cultured in anaerobic bioreactors controlled at $\mathrm{pH} 6.5$ supplemented with either lactose or total human milk (HM) carbohydrates. B. infantis monoculture reached maximal cell density around $12 \mathrm{~h}$ at growth rate around $0.33 \mathrm{~h}^{-1}\left(\mathrm{OD}_{\max }=1.40 \pm 0.38\right.$ on lactose and $\mathrm{OD}_{\max }=$ $1.37 \pm 0.25$ on total HM carbohydrates) (Figure 2). For A. caccae monoculture, no growth or substrate breakdown was detected in identical media $\left(\mathrm{OD}_{\max }=0.02 \pm 0.01\right.$ on lactose and $\mathrm{OD}_{\max }=0.03 \pm 0.02$ on total $\mathrm{HM}$ carbohydrates) (Supplementary Table S1). The co-culture of B. infantis with A. caccae reached a growth rate of $0.70 \mathrm{~h}^{-1}$ on lactose and $0.72 \mathrm{~h}^{-1}$ on total HM carbohydrates, with maximal optical density at $11 \mathrm{~h}$ on lactose $\left(\mathrm{OD}_{\max }=3.63 \pm 0.61\right)$ and at $9 \mathrm{~h}$ on total HM carbohydrates $\left(\mathrm{OD}_{\max }=3.54 \pm 0.60\right)$. The cell density of the co-cultures was higher than the monocultures initially but significantly decreased after about $12 \mathrm{~h}$ of
A Genus level

Bifidobacterium

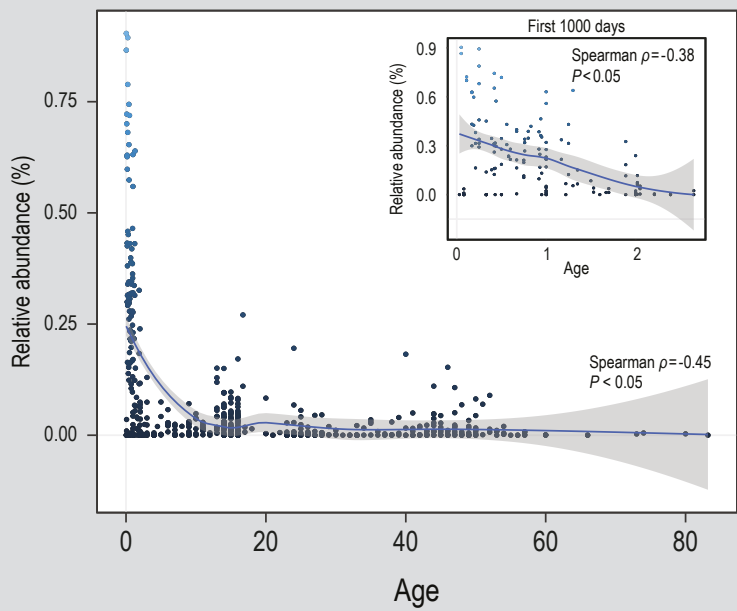

C Family level

Bifidobacteriaceae

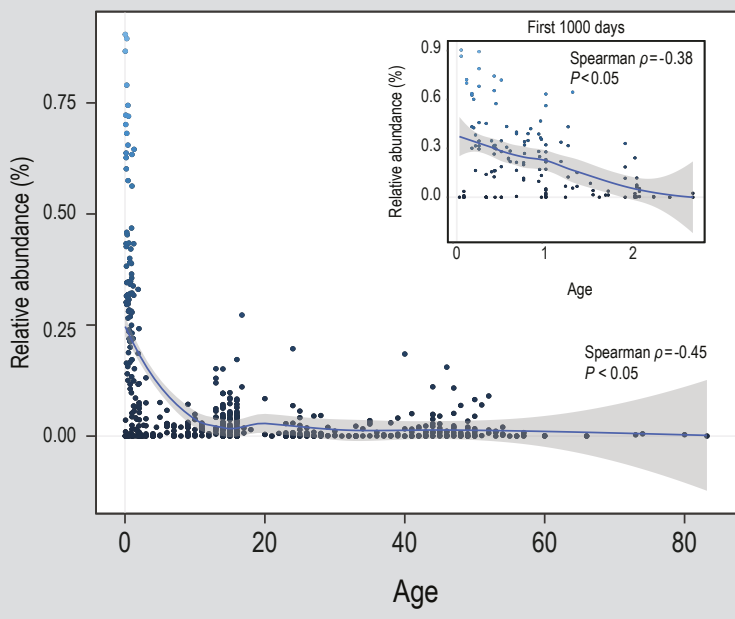

B

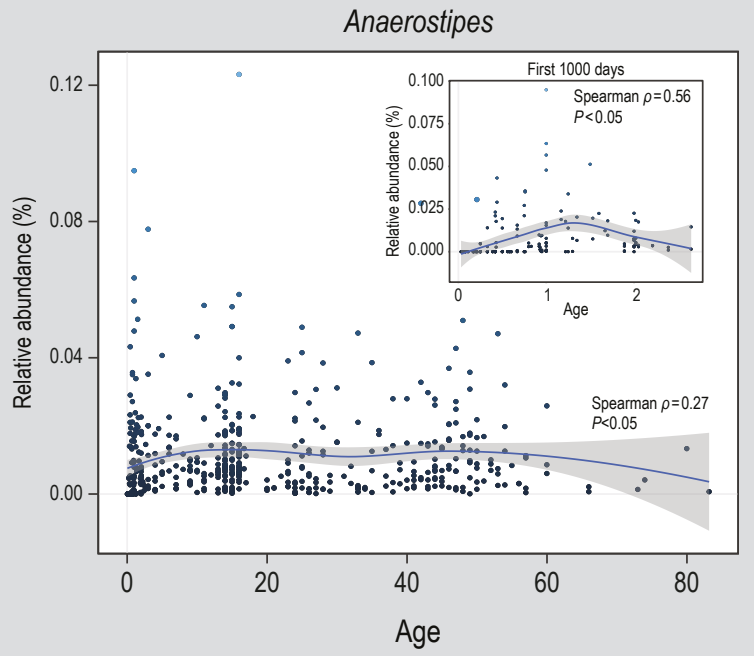

D Lachnospiraceae

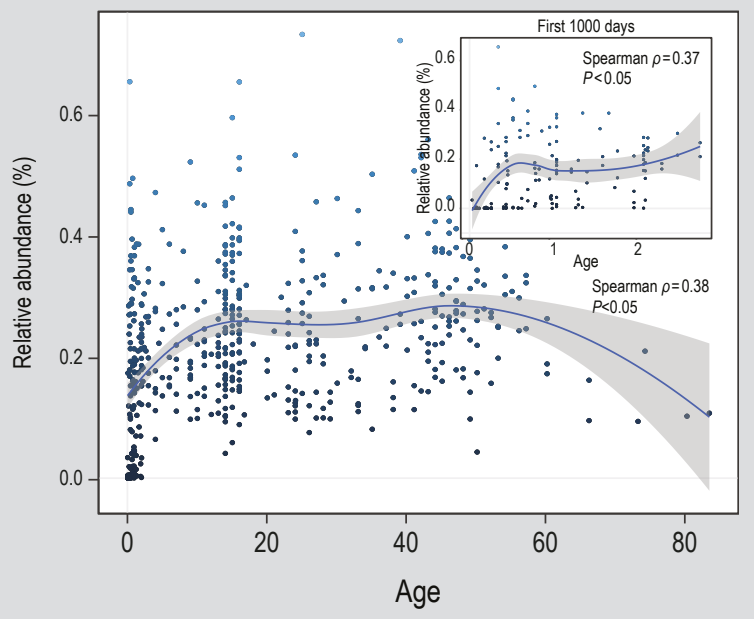

Figure 1. Occurrence of (A) Bifidobacterium and (B) Anaerostipes genus, as well as (C) Bifidobacteriaceae and (D) Lachnospiraceae family in the gut microbiota across age. The plot was generated from a published dataset (Yatsunenko et al., 2012) using $R$ package ggplot 2 version 2.2.1. The trend lines represent the smoothed conditional means using local polynomial regression fitting (Cleveland et al., 1992). 
growth due to cell lysis. qPCR results showed that the number of $B$. infantis in the monocultures was about 2 -fold higher than in the co-cultures from $9 \mathrm{~h}$ onwards. The community dynamic in the co-cultures was monitored over time by qPCR. An equal number of $B$. infantis and $A$. caccae (around $10^{6}$ copy number $/ \mathrm{ml}$ ) was inoculated at the start of the fermentation. During the first $7 \mathrm{~h}, B$. infantis and A. caccae increased 100-fold, after which growth halted. FISH analysis of samples harvested at $11 \mathrm{~h}$ showed a B. infantis to A. caccae ratio of 1:6 (Supplementary Figure S2 and Supplementary Table S1). These results accounted for both conditions either on lactose and total HM carbohydrates supplemented cultures.

\section{Bifidobacterium infantis supports the growth and metabolism of Anaerostipes caccae on lactose and HMOs}

Substrate consumption and metabolite production were monitored over time (Figure 3). A similar profile was observed between the fermentation of lactose and total HM carbohydrates, probably because total HM carbohydrates was shown to consist of approximately $10 \%$ HMOs and $90 \%$ lactose (Supplementary Figure S1). On both substrates, the monoculture of $B$. infantis degraded the lactose present into glucose and galactose resulting in the accumulation of monomeric sugars in the supernatant (Figure 3). Lactose was completely degraded at $9 \mathrm{~h}$. At the same time point, $17.49 \pm 1.83 \mathrm{mM}$ of glucose and $15.24 \pm 2.06 \mathrm{mM}$ of galactose were detected in the media supplemented with lactose, whereas $14.77 \pm 1.59 \mathrm{mM}$ of glucose and $10.91 \pm 1.77 \mathrm{mM}$ of galactose were detected in the media supplemented with total HM carbohydrates. The monomeric sugars were fully consumed after $31 \mathrm{~h}$. B. infantis produced acetate (56.96 $\pm 4.48 \mathrm{mM}$ on lactose and $50.76 \pm 3.23 \mathrm{mM}$ on total HM carbohydrates), lactate $(22.73 \pm 3.02 \mathrm{mM}$ on lactose and $17.69 \pm 1.21 \mathrm{mM}$ on total HM carbohydrates) and formate $(6.56 \pm 0.09 \mathrm{mM}$ on lactose and $8.04 \pm 0.21 \mathrm{mM}$ on total HM carbohydrates) as the major end metabolites. The final acetate to lactate ratio for $B$. infantis on lactose was 2.4:1 and 2.6:1 on total HM carbohydrates.

The co-culture of B. infantis with A. caccae also degraded lactose completely within $9 \mathrm{~h}$. However, the co-cultures depleted glucose and galactose faster compared to the monocultures of $B$. infantis. The concentration of monomeric sugars peaked around $7 \mathrm{~h}$ in media supplemented with lactose, with $4.62 \pm 1.21 \mathrm{mM}$ glucose and $7.10 \pm 0.97 \mathrm{mM}$ galactose. In media supplemented with the total HM
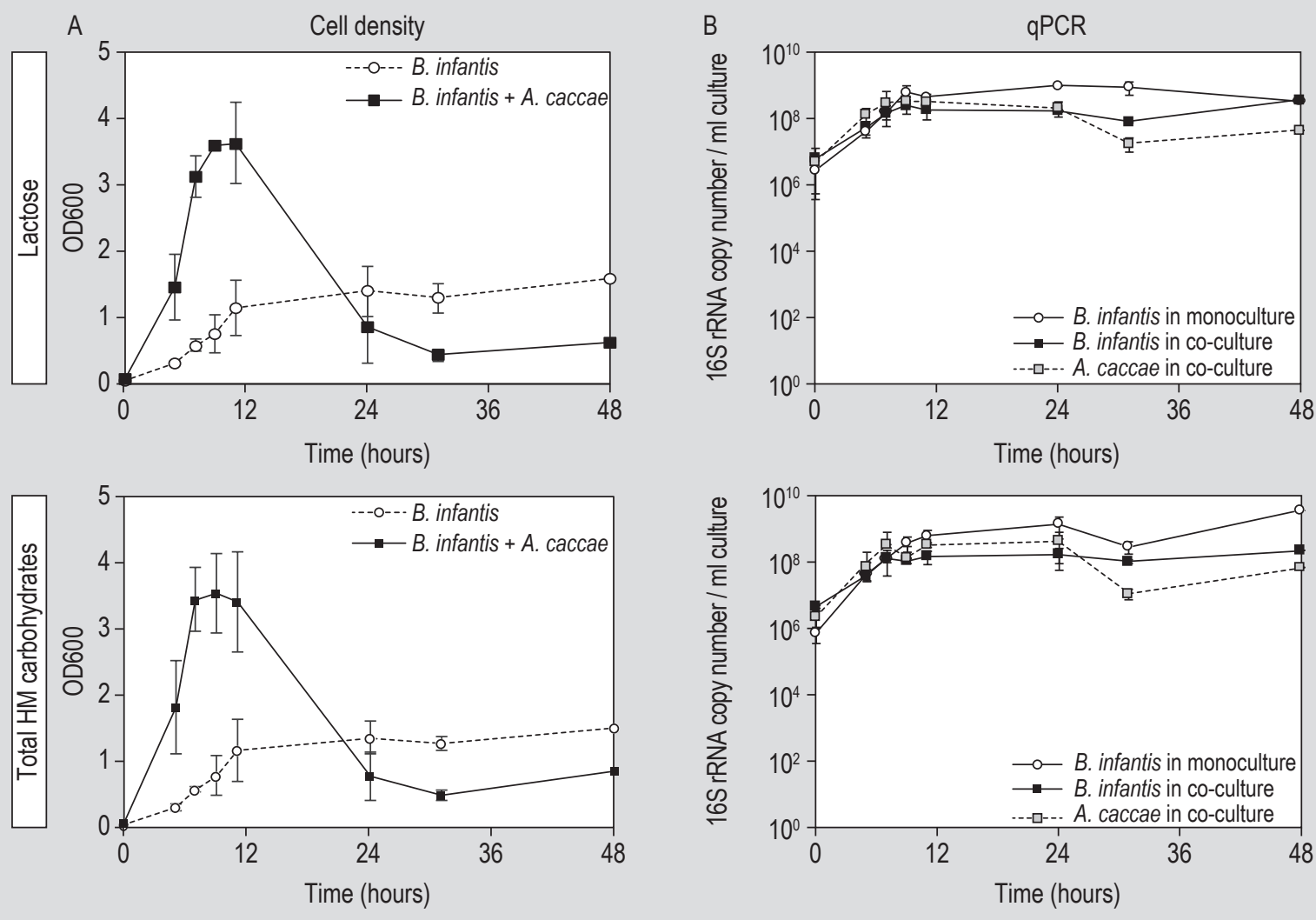

Figure 2. Bifidobacterium infantis supported the growth of Anaerostipes caccae in human milk carbohydrates. (A) The optical density (OD600) indicating bacterial growth and (B) qPCR results showing the microbial composition in the mono- and co-cultures over time with lactose or with total human milk (HM) carbohydrates. Error bars represent the standard deviation for biological triplicates, except for time point $31 \mathrm{~h}(\mathrm{n}=2)$ and $48 \mathrm{~h}(\mathrm{n}=1)$. 

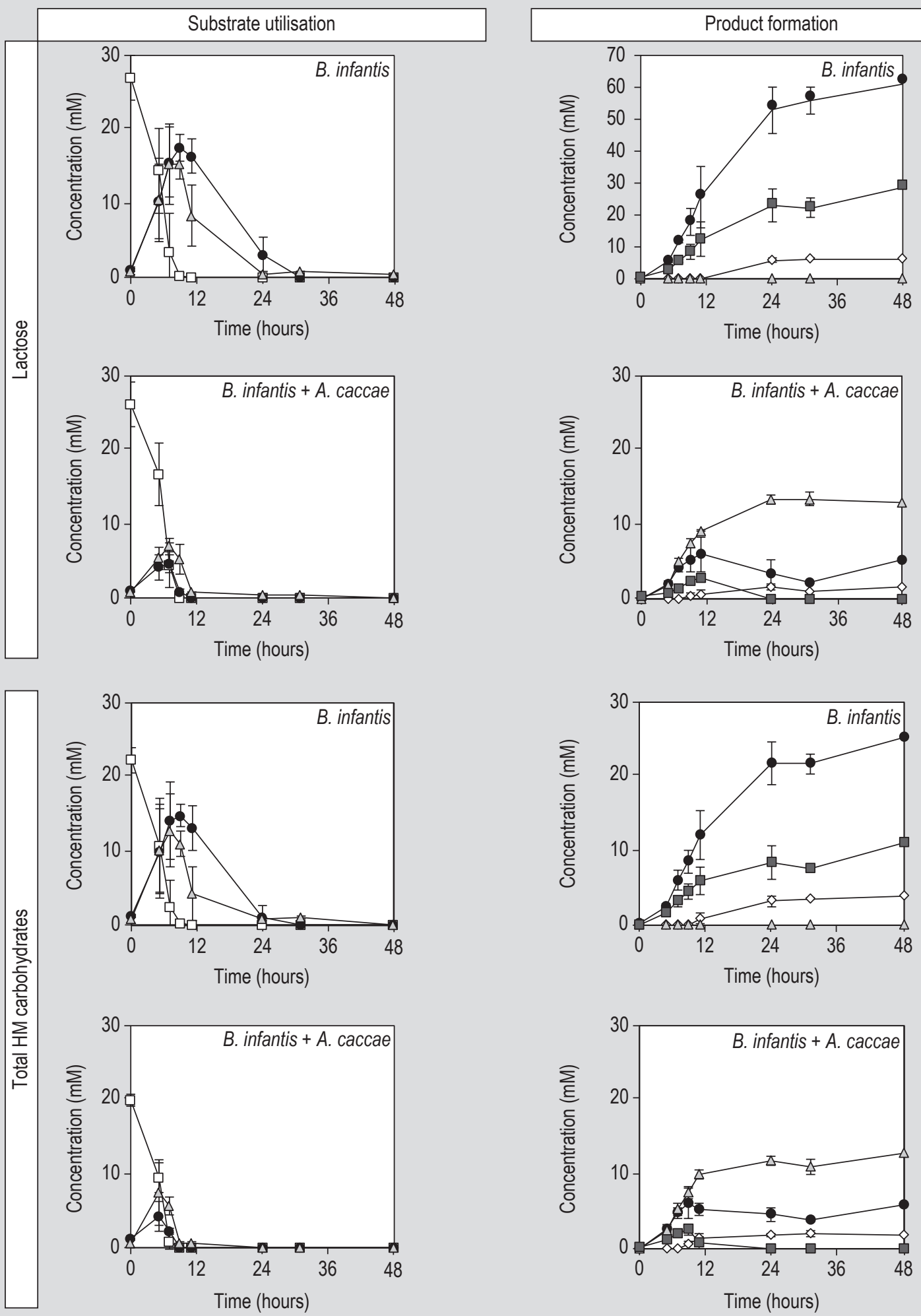

$\neg \square$ Lactose $\multimap$ Glucose $\neg-$ Galactose

$\multimap$ Formate $\multimap$ Acetate $\neg-$ Butyrate $\multimap-$ Lactate

Figure 3. Bifidobacterium infantis supported butyrate production of Anaerostipes caccae. The substrate utilisation and product formation of co-cultures on lactose or total HM carbohydrates. Error bars represent the standard deviation for biological triplicates, except for time point $31 \mathrm{~h}(\mathrm{n}=2)$ and $48 \mathrm{~h}(\mathrm{n}=1)$. 
carbohydrates, the maximum concentration for glucose $(4.20 \pm 2.10 \mathrm{mM})$ and galactose $(7.39 \pm 4.45 \mathrm{mM})$ was detected after $5 \mathrm{~h}$. Only traces of monomeric sugars were still detectable after $9 \mathrm{~h}$. The major end products of fermentation in the co-cultures were butyrate $(31.39 \pm 2.15 \mathrm{mM}$ on lactose and $25.80 \pm 2.45 \mathrm{mM}$ on total HM carbohydrates), acetate (5.44 $\pm 0.30 \mathrm{mM}$ on lactose and $9.05 \pm 0.71 \mathrm{mM}$ on total HM carbohydrates) and formate $(2.53 \pm 0.16 \mathrm{mM}$ on lactose and $4.78 \pm 1.16 \mathrm{mM}$ on total HM carbohydrates). Butyrate, the signature metabolic end product of $A$. caccae reached levels of $31.39 \pm 1.36 \mathrm{mM}$ with lactose and $27.68 \pm 1.38 \mathrm{mM}$ with total HM carbohydrates at $24 \mathrm{~h}$. In contrast to the B. infantis monocultures, no lactate was detected after $11 \mathrm{~h}$ in the co-cultures.

The low molecular weight HMOs structures in the total HM carbohydrates were determined by LC-ESI$\mathrm{MS}^{2}$ for 0 and $24 \mathrm{~h}$ cultures in order to understand the specific glycan utilisation by these bacteria (Figure 4). The monoculture of $B$. infantis completely degraded the full range of neutral trioses (including 2'-fucosyllactose [2'-FL] and 3-fucosyllactose [3-FL]), tetraoses (including difucosyllactose [DFL], lacto-N-tetraose [LNT], lacto-Nneotetraose $[\mathrm{LNnT}]$ ), pentaoses (lacto- $\mathrm{N}$-fucopentaose I [LNFP I], lacto-N-fucopentaose II [LNFP II], lacto-Nfucopentaose III [LNFP III], lacto-N-fucopentaose V [LNFP V]), and acidic trioses (including 3'-sialyllactose [3'-SL] and 6'-sialyllactose [6'-SL]). No degradation of HMOs was observed in the A. caccae monoculture. On the other hand, the glycan utilisation pattern in the co-culture was identical to the profile of $B$. infantis monoculture indicative of the degrader role of $B$. infantis in the cocultures. In addition, substrate quantification using HPLC showed that specific HMO-derived sugars, such as GlcNAc and fucose, were not detected, likely because these stay below the detection limit $(0.5 \mathrm{mM})$ or due to overlap with other HPLC peaks.

\section{Microbial cross-feeding results in a shift of acids pool}

The cultures were maintained at $\mathrm{pH} 6.5$ with the addition of $2 \mathrm{M} \mathrm{NaOH}$. B. infantis monocultures required a higher amount of base addition compared to the co-culture with A. caccae (Figure 5A). The acidification of the cultures was reflected in the composition of acids. The total amount of acids at $31 \mathrm{~h}$ were higher in the monocultures $(86.76 \pm 7.78 \mathrm{mM}$ on lactose and $76.75 \pm 3.86 \mathrm{mM}$ on total HM carbohydrates) in comparison to the co-cultures $(39.36 \pm 1.68 \mathrm{mM}$ on lactose and $39.88 \pm 3.97 \mathrm{mM}$ on total $\mathrm{HM}$ carbohydrates). Furthermore, as a result of microbial crossfeeding in the co-cultures, lactate $(\mathrm{pKa}=3.86)$ produced by $B$. infantis monocultures was converted to butyrate $(\mathrm{pKa}=4.82)$. The $\mathrm{pKa}$ value indicates the quantitative measurement of the strength of an acid in the solution with lower values for stronger acid. As the $\mathrm{pKa}$ values are expressed in log scale, the decrease by one numerical value in lactate compared to butyrate may result in a 10-fold higher concentration of soluble protons. To investigate the dynamic of $\mathrm{pH}$ in early life, the data from Wopereis et al. (2017) was employed. We observed that the faecal $\mathrm{pH}$ for infants $(\mathrm{n}=138)$ increased from $\mathrm{pH} 5.7$ at 1 week to $\mathrm{pH}$ 6.0 at 6 months of life (Figure 5B).

\section{Discussion}

The infant gut ecosystem is highly dynamic and marked by the succession of bacterial species (Backhed et al., 2015). At this important window of growth and development, breast-feeding generally leads to the efficient colonisation of bifidobacteria in early life (Backhed et al., 2015). Bifidobacteria could prime the development of gut barrier function and immune maturation (Ruiz et al., 2017), as well as play an important ecological role in the establishment of the gut microbiota. Here, we showed that B. infantis could support the metabolism and growth of other important species in early life, such as the butyrate-producing A. caccae via cross-feeding. This microbial cross-feeding resulted in the shift of the acids pool and butyrate production. Physiologically, butyrate is associated with the enhancement of colonic barrier function and it could regulate host immune and metabolic state by signalling through G-protein-coupled receptors and by inhibiting histone deacetylase (Bolognini et al., 2016; Fellows et al., 2018; Geirnaert et al., 2017; Koh et al., 2016). Although the mechanistic evidences for butyrate are mostly generated from adult studies, a gradual shift in the ecosystem with slow induction of butyrate could be important for the maturation of the infant gut.

The dominance of bifidobacteria is often observed in the infant gut microbiota (Tannock et al., 2016). Infantassociated bifidobacteria have evolved to be competitive in utilising human milk as substrate by employing a large arsenal of enzymes to metabolise HMOs (O'Callaghan and Van Sinderen, 2016). We showed that $B$. infantis effectively degrades the full range of the low molecular weight HMOs structures including neutral trioses, tetraoses, and pentaoses as well as acidic trioses. This is consistent with the unique HMOs utilisation capability of $B$. infantis by encoding a $43 \mathrm{~kb}$ gene cluster that carries the genes for different oligosaccharides transport proteins and glycosyl hydrolases (Underwood et al., 2014). However, we did not detect the production of 1,2-propanediol from fucosylated HMOs, as demonstrated by Bunesova et al. (2016). No signal peptide or transmembrane domain was predicted for $B$. infantis enzymes involved in the cleavage of the monitored HMOs structures (Supplementary Table S2), indicating intracellular degradation of these substrates (Sela et al., 2008). The monosaccharides including glucose and galactose were detected in the growth media of mono- and co-cultures (Figure 3) potentially released upon cell lysis. Furthermore, the distinct 'bifid shunt pathway' centred 


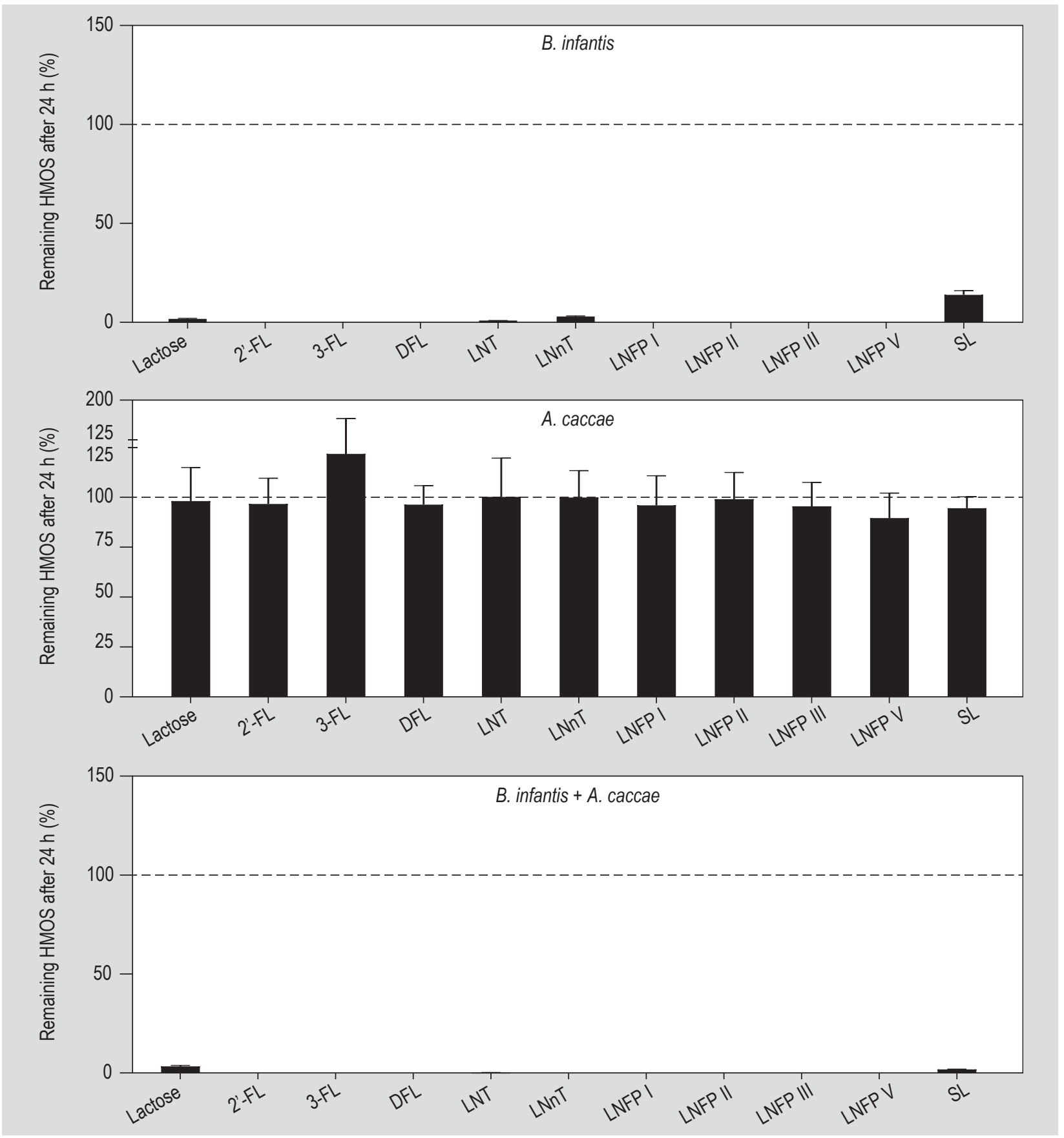

Figure 4. Bifidobacterium infantis monoculture and co-culture with Anaerostipes caccae utilised the full range of low molecular weight HMOs. Error bars represent the error propagation for mean of three (for $A$. caccae) or four (for $B$. infantis and $B$. infantis $+A$. caccae) biological replicates measured in technical triplicates. The HMOs structures and glycosidic linkages are depicted according to Varki et al. (2015). 2'-FL = 2'-fucosyllactose; 3-FL = 3-fucosyllactose; DFL = difucosyllactose; LNT = lacto-N-tetraose; LNnT = lacto-N-neotetraose; LNFP I = lacto-N-fucopentaose I; LNFP II = lacto-N-fucopentaose II; LNFP III = lacto-N-fucopentaose III; LNFP V = lacto-N-fucopentaose V; SL = sialyllactose.

around the enzyme fructose-6-phosphate phosphoketolase (F6PPK) could also account for the competitiveness of bifidobacteria (O'Callaghan and Van Sinderen, 2016). The fermentation of sugars via F6PPK-dependent bifid shunt pathway yields more energy compared to the usual glycolysis or Emden-Meyerhof Parnas pathway which could give bifidobacteria an additional advantage compared to other gut bacteria (Palframan et al., 2003).

Lactose and HMOs fermentation by bifidobacteria results in acetate and lactate as major end products. Although majority of lactose from milk is expected to be 


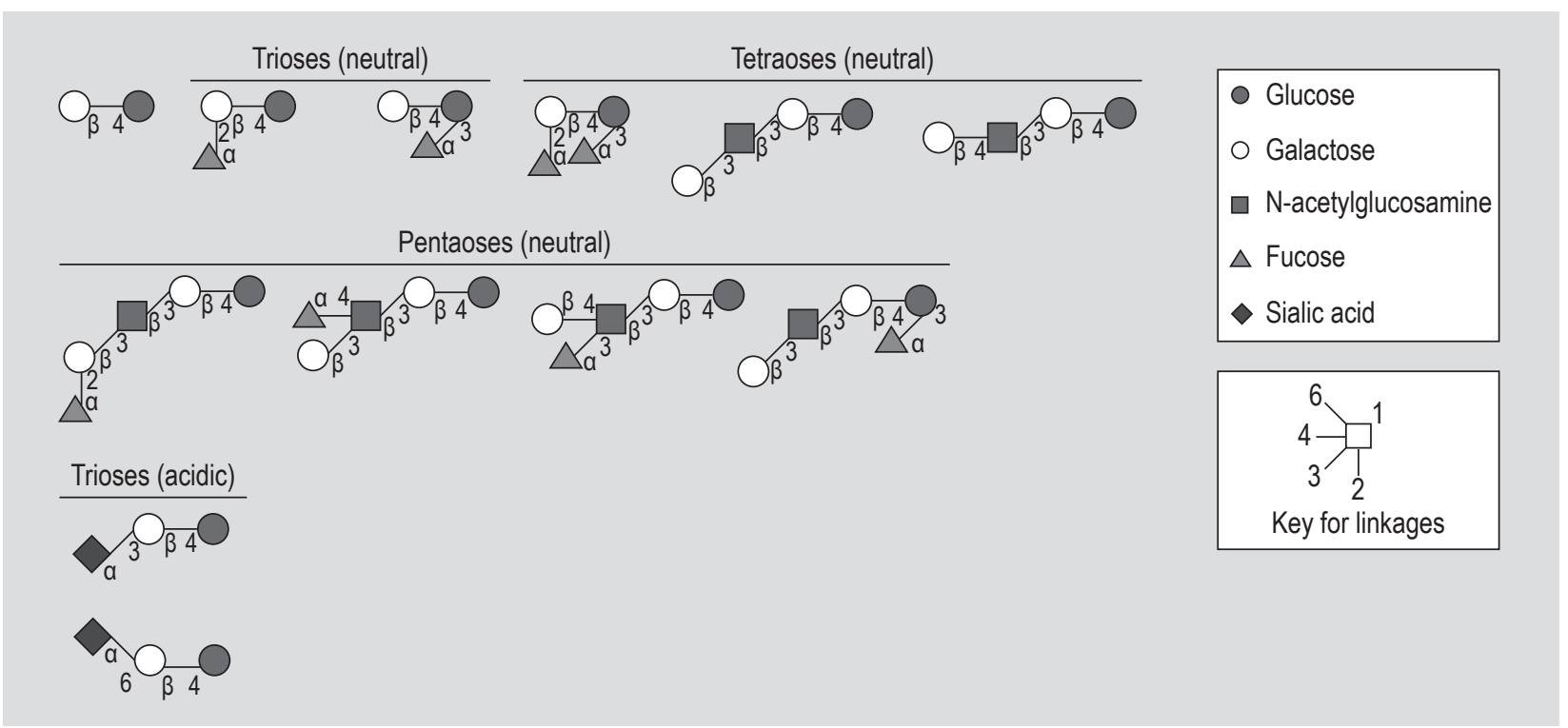

Figure 4. Continued.

degraded in the upper gastrointestinal tract of infants, colonic fermentation of lactose is still relevant especially for lactose-deficient subjects and lactose core could be liberated from HMOs-degradation (Venema, 2012). In addition to bifidobacteria, other primary colonisers like Lactobacillus, Streptococcus, Staphylococcus, and Enterococcus spp. also contribute to lactate production in the infant gut (Pham et al., 2017). In the gut of breastfed infants, the overall digestion and fermentation lead to a relatively high concentration of acetate and lactate with a low pH (Oozeer et al., 2013; Pham et al., 2016). The $\mathrm{pH}$ of the luminal content has a significant impact on the microbiota composition (Duncan et al., 2009). Various bacterial groups have been shown to be inhibited by a low $\mathrm{pH}$, such as opportunistic pathogens including Salmonella Typhimurium, Staphylococcus aureus, Escherichia coli, Enterococcus faecalis, Pseudomonas aeruginosa, and Klebseilla pneumoniae (Van Limpt et al., 2004) as well as Bacteroides spp. (Duncan et al., 2009; Walker et al., 2005). In contrast, a low $\mathrm{pH}$ may promote butyrate production and the butyrogenic community (Reichardt et al., 2017; Walker et al., 2005). Given the above, the circumstances in the infant gut seems to be in favour of the colonisation of butyrate-producers.

In the first months of life butyrate levels in the faeces are generally low (Oozeer et al., 2013; Pham et al., 2016) and the major adult-type butyrate-producing population (Roseburia and Faecalibacterium spp.) remained undetectable up to 30 days postnatal (Jost et al., 2012). We observed an increase of relative abundance for Lachnospiraceae family and Anaerostipes genus in the first year of life (Yatsunenko et al., 2012). The majority of butyrate-producing bacteria from the Lachnospiraceae and Ruminococcaceae are not capable of utilising HMOs (Sheridan et al., 2016). For
A. caccae, no growth or metabolism was detected in the media containing lactose and HMOs. These subdominant butyrogenic bacteria in the infant gut could depend on cross-feeding with species like bifidobacteria. Our results indicate that $A$. caccae could utilise the monomeric sugars and end products like acetate and lactate derived from B. infantis for metabolic activity and growth (Duncan et al. 2004). A. caccae is known to convert $1 \mathrm{~mol}$ of acetate and $2 \mathrm{~mol}$ of lactate to yield $1.5 \mathrm{~mol}$ of butyrate (Duncan et al., 2004). Our previous study (Belzer et al., 2017) demonstrated that $A$. caccae in glucose has a specific growth rate around $0.2 \mathrm{~h}^{-1}$. Glucose supplemented with $10 \mathrm{mM}$ of acetate enhanced the growth rate of $A$. caccae to around $0.6 \mathrm{~h}^{-1}$. In the monocultures of B. infantisantis (Figure 3), we showed that monosaccharides (glucose and galactose) were detected in the supernatant at the intermediary stage of fermentation, with acetate and lactate as end metabolites. We deduced that the growth rate for $A$. caccae in co-culture with $B$. infantis could be on par of the previously tested condition with glucose and acetate, due to the presence of key substrate to support the growth of $A$. caccae. This is supported by the observation that the total carbon in the end metabolites of the co-cultures was about 1.5-fold lower compared to the $B$. infantis mono-culture, indicating carbon utilisation for the growth of $A$. caccae to synthesise cell components. This metabolic interaction could also benefit the microbial community by reducing the metabolic burden (Seth and Taga, 2014), shown by the formation of a relatively weaker acid pool. The infant faecal $\mathrm{pH}$ showed an increasing trend with age (Figure 5) (Wopereis et al., 2017), potentially due to the shift of colonic acids pool driven by changes in diet, microbiota composition and function, and physiological development. Faecal $\mathrm{pH}$ provides an indication on the acids pool although other factor such as the production of alkaline molecules, i.e. ammonia could 


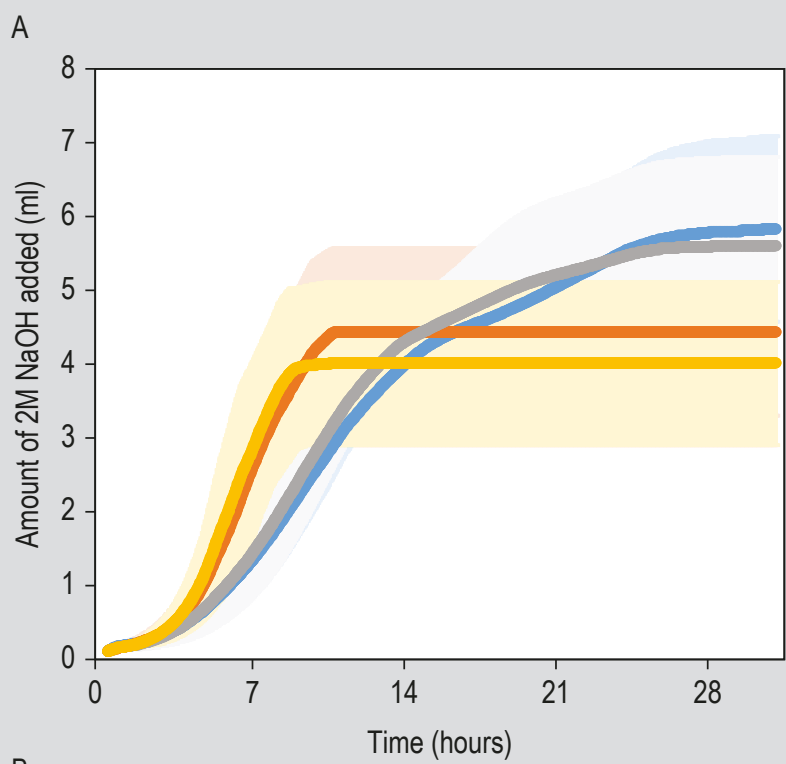

\begin{tabular}{|c|c|}
\multicolumn{1}{c}{$\mathrm{HA} \rightleftharpoons \mathrm{A}^{-}+\mathrm{H}^{+}$} \\
\hline SCFA & $\mathrm{pKa}$ \\
\hline : Lactate & 3.86 \\
\hline$\vdots$ Acetate & 4.76 \\
\hline : Butyrate & 4.82 \\
\hline
\end{tabular}

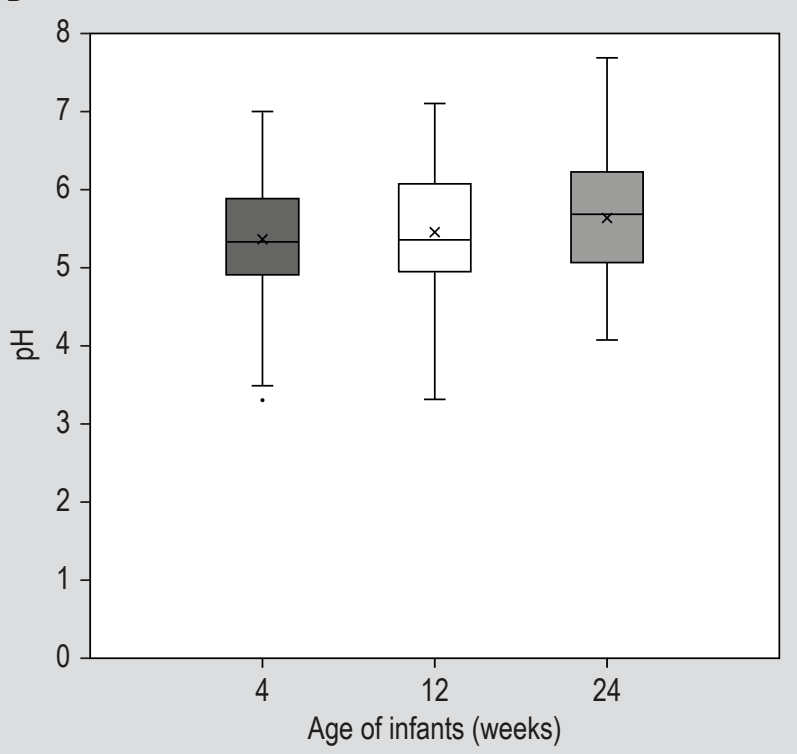

\section{B. infantis \\ $\rightarrow$ Lactose $\rightarrow$ - Total HM carbohydrates \\ B. infantis + A. caccae \\ $\rightarrow$ Lactose $\rightarrow$ Total HM carbohydrates}

Figure 5. The acidification of cultures and faecal pH. (A) Base $(2 \mathrm{M} \mathrm{NaOH})$ added to maintain the anaerobic chemostat at pH 6.5 . The shaded error bars indicate standard deviation for biological triplicates. (B) The faecal $\mathrm{pH}$ for infants $(\mathrm{n}=138)$. Data adapted from Wopereis et al. (2017).

affect the acidity level. Osuka et al. (2012) showed that the total organic acid was increased in acidic faeces $(\mathrm{pH}<6.0)$ and decreased in alkaline faeces $(\mathrm{pH}>7.2)$. Specifically, lactate, succinate, and formate were the main contributors to acidity in acidic faeces. Acetate and lactate as well as a small amount of propionate and butyrate can be detected in the faeces of infants (Pham et al., 2016; Wopereis et al., 2017). Whereas, the typical short chain fatty acids (SCFA) ratio in adult faeces is around 3:1:1 for acetate, propionate and butyrate respectively (Schwiertz et al., 2010; Scott et al., 2011). The shift of the SCFA pool goes hand in hand with the transition of the gut microbiota, likely induced by dietary changes. Upon weaning, the diversification of indigestible fibres due to the introduction of solid foods results in conditions leading to the decrease of the relative numbers of bifidobacteria and the relative increase of Lachnospiraceae, Ruminococcaceae, and Bacteroides spp. (Laursen et al., 2017).

Although the contributing factors to the progression from bifidobacteria dominant community to Firmicutes and Bacteroides dominant community are not well understood, the well-orchestrated transition is important for health. An aberrant microbial composition and/or SCFA production are associated with colicky symptoms and atopy diseases in infants (Arrieta et al., 2015; De Weerth et al., 2013; Pham et al., 2017; Stokholm et al., 2018; Wopereis et al., 2017). We demonstrated the role of $B$. infantis in driving 
the butyrogenic trophic chain by metabolising human milk carbohydrates. This microbial cross-feeding is indicative of the key ecological role of bifidobacteria as substrates provider for subdominant butyrate-producing bacteria. The compromised health outcomes as a result of the delayed transition from bifidobacteria-dominant to butyrogenic microbial community highlight the importance of proper developmental stages in the infant gut.

\section{Supplementary material}

Supplementary material can be found online at https://doi. org/10.3920/BM2020.0005.

Figure S1. The GPC-RI chromatogram for total human milk carbohydrates showing a composition of approximately $90 \%$ of lactose, $10 \%$ of both acidic and neutral HMOs as well as traces of monosaccharides.

Figure S2. Bifidobacterium infantis supported the growth of Anaerostipes caccae in human milk carbohydrates: fluorescent in situ hybridisation of co-cultures at $11 \mathrm{~h}$.

Table S1. The optical density, substrates and end products detected in Anaerostipes caccae monoculture on lactose and total HM carbohydrates and media blanks at the end of fermentation.

Table S2. Human milk oligosaccharide structures and prediction of degradation by Bifidobacterium infantis ATCC15697.

\section{Conflict of interest}

This project is financially supported by Nutricia Research. MM, BB, RB, HW, KvL, ST, BS and JK are employed by Nutricia Research.

\section{Acknowledgements}

We thank Heleen de Weerd for 16S rRNA amplicon sequencing analysis.

\section{References}

Arrieta, M.C., Stiemsma, L.T., Amenyogbe, N., Brown, E.M. and Finlay, B., 2014. The intestinal microbiome in early life: health and disease. Frontiers in Immunology 5: 427. https://doi.org/10.3389/ fimmu.2014.00427

Arrieta, M.C., Stiemsma, L.T., Dimitriu, P.A., Thorson, L., Russell, S., YuristDoutsch, S., Kuzeljevic, B., Gold, M.J., Britton, H.M., Lefebvre, D.L., Subbarao, P., Mandhane, P., Becker, A., McNagny, K.M., Sears, M.R., Kollmann, T., Investigators, C.S., Mohn, W.W., Turvey, S.E. and Brett Finlay, B., 2015. Early infancy microbial and metabolic alterations affect risk of childhood asthma. Science Translational Medicine 7: 307ra152. https://doi.org/10.1126/scitranslmed.aab2271
Backhed, F., Roswall, J., Peng, Y., Feng, Q., Jia, H., Kovatcheva-Datchary, P., Li, Y., Xia, Y., Xie, H., Zhong, H., Khan, M.T., Zhang, J., Li, J., Xiao, L., Al-Aama, J., Zhang, D., Lee, Y.S., Kotowska, D., Colding, C., Tremaroli, V., Yin, Y., Bergman, S., Xu, X., Madsen, L., Kristiansen, K., Dahlgren, J. and Jun, W., 2015. Dynamics and stabilization of the human gut microbiome during the first year of life. Cell Host and Microbe 17: 690-703. https://doi.org/10.1016/j.chom.2015.04.004 Belenguer, A., Duncan, S.H., Calder, A.G., Holtrop, G., Louis, P., Lobley, G.E. and Flint, H.J., 2006. Two routes of metabolic cross-feeding between Bifidobacterium adolescentis and butyrate-producing anaerobes from the human gut. Applied and Environmental Microbiology 72: 3593-3599. https://doi.org/10.1128/ Aem.72.5.3593-3599.2006

Bode, L., 2012. Human milk oligosaccharides: every baby needs a sugar mama. Glycobiology 22: 1147-1162. https://doi.org/10.1093/ glycob/cws074

Bolognini, D., Tobin, A.B., Milligan, G. and Moss, C.E., 2016. The pharmacology and function of receptors for short-chain fatty acids. Molecular Pharmacology 89: 388-398. https://doi.org/10.1124/ mol.115.102301

Bunesova, V., Lacroix, C. and Schwab, C., 2017. Mucin cross-feeding of infant bifidobacteria and Eubacterium hallii. Microbial Ecology. https://doi.org/10.1007/s00248-017-1037-4.

Caporaso, J.G., Kuczynski, J., Stombaugh, J., Bittinger, K., Bushman, F.D., Costello, E.K., Fierer, N., Pena, A.G., Goodrich, J.K., Gordon, J.I., Huttley, G.A., Kelley, S.T., Knights, D., Koenig, J.E., Ley, R.E., Lozupone, C.A., McDonald, D., Muegge, B.D., Pirrung, M., Reeder, J., Sevinsky, J.R., Turnbaugh, P.J., Walters, W.A., Widmann, J., Yatsunenko, T., Zaneveld, J. and Knight, R., 2010. QIIME allows analysis of high-throughput community sequencing data. Nature Methods 7: 335-336. https://doi.org/10.1038/nmeth.f.303

Cheng, J., Ringel-Kulka, T., Heikamp-de Jong, I., Ringel, Y., Carroll, I., de Vos, W.M., Salojarvi, J. and Satokari, R., 2015. Discordant temporal development of bacterial phyla and the emergence of core in the fecal microbiota of young children. ISME Journal 10: 1002-1014. https://doi.org/10.1038/ismej.2015.177

Cleveland, W.S., Grosse, E. and Shyu, W.M., 1992. Local regression models. In: Chambers, J.M. and Hastie, T.J. (eds.) Statistical models in S. Chapmann \& Hall, New York, NY, USA, pp. 309-376.

Cole, J.R., Wang, Q., Cardenas, E., Fish, J., Chai, B., Farris, R.J., KulamSyed-Mohideen, A.S., McGarrell, D.M., Marsh, T., Garrity, G.M. and Tiedje, J.M., 2009. The Ribosomal Database Project: improved alignments and new tools for rRNA analysis. Nucleic Acids Research 37: D141-145. https://doi.org/10.1093/nar/gkn879

Coppa, G.V., Gabrielli, O., Pierani, P., Catassi, C., Carlucci, A. and Giorgi, P.L., 1993. Changes in carbohydrate composition in human milk over 4 months of lactation. Pediatrics 91: 637-641.

De Vuyst, L. and Leroy, F., 2011. Cross-feeding between bifidobacteria and butyrate-producing colon bacteria explains bifdobacterial competitiveness, butyrate production, and gas production. International Journal of Food Microbiology 149: 73-80. https:// doi.org/10.1016/j.ijfoodmicro.2011.03.003

de Weerth, C., Fuentes, S., Puylaert, P. and de Vos, W.M., 2013. Intestinal microbiota of infants with colic: development and specific signatures. Pediatrics 131: e550-558. https://doi.org/10.1542/ peds.2012-1449 
Delroisse, J.M., Boulvin, A.L., Parmentier, I., Dauphin, R.D., Vandenbol, M. and Portetelle, D., 2008. Quantification of Bifidobacterium spp. and Lactobacillus spp. in rat fecal samples by real-time PCR. Microbiological Research 163: 663-670.

Dinoto, A., Suksomcheep, A., Ishizuka, S., Kimura, H., Hanada, S., Kamagata, Y., Asano, K., Tomita, F. and Yokota, A., 2006. Modulation of rat cecal microbiota by administration of raffinose and encapsulated Bifidobacterium breve. Applied and Environmental Microbiology 72: 784-792. https://doi.org/10.1128/AEM.72.1.784792.2006

Duncan, S.H., Louis, P. and Flint, H.J., 2004. Lactate-utilizing bacteria, isolated from human feces, that produce butyrate as a major fermentation product. Applied Environmental Microbiology 70: 5810-5817. https://doi.org/10.1128/AEM.70.10.5810-5817.2004

Duncan, S.H., Louis, P., Thomson, J.M. and Flint, H.J., 2009. The role of $\mathrm{pH}$ in determining the species composition of the human colonic microbiota. Environmental Microbiology 11: 2112-2122. https:// doi.org/10.1111/j.1462-2920.2009.01931.x

Edgar, R.C., 2010. Search and clustering orders of magnitude faster than BLAST. Bioinformatics 26: 2460-2461. https://doi.org/10.1093/ bioinformatics/btq461

Engfer, M.B., Stahl, B., Finke, B., Sawatzki, G. and Daniel, H., 2000. Human milk oligosaccharides are resistant to enzymatic hydrolysis in the upper gastrointestinal tract. American Journal of Clinical Nutrition 71: 1589-1596.

Falony, G., Vlachou, A., Verbrugghe, K. and De Vuyst, L., 2006. Crossfeeding between Bifidobacterium longum BB536 and acetateconverting, butyrate-producing colon bacteria during growth on oligofructose. Applied and Environmental Microbiology 72: 78357841. https://doi.org/10.1128/Aem.01296-06

Feehley, T., Plunkett, C., Bao, R., Hong, S., Culleen, E., Belda-Ferre, P., Campbell, E., Aitoro, R., Nocerino, R., Paparo, L., Andrade, J., Antonopoulos, D., Berni Canani, R. and Nagler, C., 2019. Healthy infants harbor intestinal bacteria that protect against food allergy. Nature Medicine 25. https://doi.org/10.1038/s41591-018-0324-z

Fellows, R., Denizot, J., Stellato, C., Cuomo, A., Jain, P., Stoyanova, E., Balázsi, S., Hajnády, Z., Liebert, A., Kazakevych, J., Blackburn, H., Corrêa, R.O., Fachi, J.L., Sato, F.T., Ribeiro, W.R., Ferreira, C.M., Perée, H., Spagnuolo, M., Mattiuz, R., Matolcsi, C., Guedes, J., Clark, J., Veldhoen, M., Bonaldi, T., Vinolo, M.A.R. and VargaWeisz, P., 2018. Microbiota derived short chain fatty acids promote histone crotonylation in the colon through histone deacetylases. Nature Communications 9: 105. https://doi.org/10.1038/s41467017-02651-5

Gabrielli, O., Zampini, L., Galeazzi, T., Padella, L., Santoro, L., Peila, C., Giuliani, F., Bertino, E., Fabris, C. and Coppa, G.V., 2011. Preterm milk oligosaccharides during the first month of lactation. Pediatrics 128: e1520-1531. https://doi.org/10.1542/peds.2011-1206

Geirnaert, A., Calatayud, M., Grootaert, C., Laukens, D., Devriese, S., Smagghe, G., De Vos, M., Boon, N. and Van de Wiele, T., 2017. Butyrate-producing bacteria supplemented in vitro to Crohn's disease patient microbiota increased butyrate production and enhanced intestinal epithelial barrier integrity. Scientific Reports 7: 11450. https://doi.org/10.1038/s41598-017-11734-8
Hayashi, H., Sakamoto, M. and Benno, Y., 2004. Evaluation of three different forward primers by terminal restriction fragment length polymorphism analysis for determination of fecal Bifidobacterium spp. in healthy subjects. Microbiology and Immunology 48: 1-6. Jost, T., Lacroix, C., Braegger, C.P. and Chassard, C., 2012. New insights in gut microbiota establishment in healthy breast fed neonates. PLoS One 7: e44595. https://doi.org/10.1371/journal.pone.0044595 Koenig, J.E., Spor, A., Scalfone, N., Fricker, A.D., Stombaugh, J., Knight, R., Angenent, L.T. and Ley, R.E., 2011. Succession of microbial consortia in the developing infant gut microbiome. Proceedings of the National Academy of Sciences of the USA 108 Suppl. 1: 45784585. https://doi.org/10.1073/pnas.1000081107

Koh, A., De Vadder, F., Kovatcheva-Datchary, P. and Backhed, F., 2016. From dietary fiber to host physiology: short-chain fatty acids as key bacterial metabolites. Cell 165: 1332-1345. https://doi.org/10.1016/j. cell.2016.05.041

Krogh, A., Larsson, B., Von Heijne, G. and Sonnhammer, E.L., 2001. Predicting transmembrane protein topology with a hidden Markov model: application to complete genomes. Journal of Molecular Biology 305: 567-580. https://doi.org/10.1006/jmbi.2000.4315

Kunz, C., Meyer, C., Collado, M.C., Geiger, L., Garcia-Mantrana, I., Bertua-Rios, B., Martinez-Costa, C., Borsch, C. and Rudloff, S., 2017. Influence of gestational age, secretor, and Lewis blood group status on the oligosaccharide content of human milk. Journal of Pediatric Gastroenterology and Nutrition 64: 789-798. https://doi. org/10.1097/MPG.0000000000001402

Laursen, M.F., Andersen, L.B.B., Michaelsen, K.F., Molgaard, C., Trolle, E., Bahl, M.I. and Licht, T.R., 2016. Infant gut microbiota development is driven by transition to family foods independent of maternal obesity. mSphere 1: e00069-15. https://doi.org/10.1128/ mSphere.00069-15

Laursen, M.F., Bahl, M.I., Michaelsen, K.F. and Licht, T.R., 2017. First foods and gut microbes. Frontiers in Microbiology 8: 356. https:// doi.org/10.3389/fmicb.2017.00356

Marcobal, A., Barboza, M., Froehlich, J.W., Block, D.E., German, J.B., Lebrilla, C.B. and Mills, D.A., 2010. Consumption of human milk oligosaccharides by gut-related microbes. Journal of Agricultural and Food Chemistry 58: 5334-5340. https://doi.org/10.1021/jf9044205 McGuire, M.K., Meehan, C.L., McGuire, M.A., Williams, J.E., Foster, J., Sellen, D.W., Kamau-Mbuthia, E.W., Kamundia, E.W., Mbugua, S., Moore, S.E., Prentice, A.M., Kvist, L.J., Otoo, G.E., Brooker, S.L., Price, W.J., Shafii, B., Placek, C., Lackey, K.A., Robertson, B., Manzano, S., Ruiz, L., Rodriguez, J.M., Pareja, R.G. and Bode, L., 2017. What's normal? Oligosaccharide concentrations and profiles in milk produced by healthy women vary geographically. American Journal of Clinical Nutrition 105: 1086-1100. https://doi. org/10.3945/ajcn.116.139980

Neville, M.C., Anderson, S.M., McManaman, J.L., Badger, T.M., Bunik, M., Contractor, N., Crume, T., Dabelea, D., Donovan, S.M., Forman, N., Frank, D.N., Friedman, J.E., German, J.B., Goldman, A., Hadsell, D., Hambidge, M., Hinde, K., Horseman, N.D., Hovey, R.C., Janoff, E., Krebs, N.F., Lebrilla, C.B., Lemay, D.G., MacLean, P.S., Meier, P., Morrow, A.L., Neu, J., Nommsen-Rivers, L.A., Raiten, D.J., Rijnkels, M., Seewaldt, V., Shur, B.D., VanHouten, J. and Williamson, P., 2012. Lactation and neonatal nutrition: defining and refining the critical questions. Journal of Mammary Gland Biology and Neoplasia 17: 167-188. https://doi.org/10.1007/s10911-012-9261-5 
O'Callaghan, A. and Van Sinderen, D., 2016. Bifidobacteria and their role as members of the human gut microbiota. Frontiers in Microbiology 7: 925. https://doi.org/10.3389/Fmicb.2016.00925

Oozeer, R., Van Limpt, K., Ludwig, T., Ben Amor, K., Martin, R., Wind, R.D., Boehm, G. and Knol, J., 2013. Intestinal microbiology in early life: specific prebiotics can have similar functionalities as humanmilk oligosaccharides. American Journal of Clinical Nutrition 98: 561S-571S. https://doi.org/10.3945/ajcn.112.038893

Palframan, R.J., Gibson, G.R. and Rastall, R.A., 2003. Carbohydrate preferences of Bifidobacterium species isolated from the human gut. Current Issues in Intestinal Microbiology 4: 71-75.

Petersen, T.N., Brunak, S., Von Heijne, G. and Nielsen, H., 2011. SignalP 4.0: discriminating signal peptides from transmembrane regions. Nature Methods 8: 785-786. https://doi.org/10.1038/nmeth.1701

Pham, V.T., Lacroix, C., Braegger, C.P. and Chassard, C., 2016. Early colonization of functional groups of microbes in the infant gut. Environmental Microbiology 18: 2246-2258. https://doi. org/10.1111/1462-2920.13316

Pham, V.T., Lacroix, C., Braegger, C.P. and Chassard, C., 2017. Lactateutilizing community is associated with gut microbiota dysbiosis in colicky infants. Scientific Reports 7: 11176. https://doi.org/10.1038/ S41598-017-11509-1

Plugge, C.M., 2005. Anoxic media design, preparation, and considerations. Methods in Enzymology 397: 3-16. https://doi. org/10.1016/S0076-6879(05)97001-8

Pruesse, E., Quast, C., Knittel, K., Fuchs, B.M., Ludwig, W., Peplies, J. and Glockner, F.O., 2007. SILVA: a comprehensive online resource for quality checked and aligned ribosomal RNA sequence data compatible with ARB. Nucleic Acids Research 35: 7188-7196. https://doi.org/10.1093/nar/gkm864

Reichardt, N., Vollmer, M., Holtrop, G., Farquharson, F.M., Wefers, D., Bunzel, M., Duncan, S.H., Drew, J.E., Williams, L.M., Milligan, G., Preston, T., Morrison, D., Flint, H.J. and Louis, P., 2017. Specific substrate-driven changes in human faecal microbiota composition contrast with functional redundancy in short-chain fatty acid production. ISME Journal 12: 610-622. https://doi.org/10.1038/ ismej.2017.196

Rios-Covian, D., Gueimonde, M., Duncan, S.H., Flint, H.J. and de los Reyes-Gavilan, C.G., 2015. Enhanced butyrate formation by crossfeeding between Faecalibacterium prausnitzii and Bifidobacterium adolescentis. FEMS Microbiology Letters 362: fnv176. https://doi. org/10.1093/femsle/fnv176

Riviere, A., Gagnon, M., Weckx, S., Roy, D. and De Vuyst, L., 2015. Mutual cross-feeding interactions between Bifidobacterium longum subsp longum NCC2705 and Eubacterium rectale ATCC 33656 explain the bifidogenic and butyrogenic effects of arabinoxylan oligosaccharides. Applied and Environmental Microbiology 81: 7767-7781. https://doi.org/10.1128/Aem.02089-15

Ruiz, L., Delgado, S., Ruas-Madiedo, P., Sanchez, B. and Margolles, A., 2017. Bifidobacteria and their molecular communication with the immune system. Frontiers in Microbiology 8: 2345. https://doi. org/10.3389/Fmicb.2017.02345
Schwab, C., Ruscheweyh, H.J., Bunesova, V., Pham, V.T., Beerenwinkel, N. and Lacroix, C., 2017. Trophic Interactions of infant bifidobacteria and eubacterium hallii during L-fucose and fucosyllactose degradation. Frontiers in Microbiology 8: 95. https:// doi.org/10.3389/fmicb.2017.00095

Schwiertz, A., Hold, G.L., Duncan, S.H., Gruhl, B., Collins, M.D., Lawson, P.A., Flint, H.J. and Blaut, M., 2002. Anaerostipes caccae gen. nov., sp. nov., a new saccharolytic, acetate-utilising, butyrateproducing bacterium from human faeces. Systematic and Applied Microbiology 25: 46-51. https://doi.org/10.1078/0723-2020-00096

Schwiertz, A., Taras, D., Schafer, K., Beijer, S., Bos, N.A., Donus, C. and Hardt, P.D., 2010. Microbiota and SCFA in lean and overweight healthy subjects. Obesity 18: 190-195. https://doi.org/10.1038/ oby. 2009.167

Scott, K.P., Duncan, S.H., Louis, P. and Flint, H.J., 2011. Nutritional influences on the gut microbiota and the consequences for gastrointestinal health. Biochemical Society Transactions 39: 10731078. https://doi.org/10.1042/BST0391073

Sela, D.A., Chapman, J., Adeuya, A., Kim, J.H., Chen, F., Whitehead, T.R., Lapidus, A., Rokhsar, D.S., Lebrilla, C.B., German, J.B., Price, N.P., Richardson, P.M. and Mills, D.A., 2008. The genome sequence of Bifidobacterium longum subsp. infantis reveals adaptations for milk utilization within the infant microbiome. Proceedings of the National Academy of Sciences of the USA 105: 18964-18969. https:// doi.org/10.1073/pnas.0809584105

Sela, D.A. and Mills, D.A., 2010. Nursing our microbiota: molecular linkages between bifidobacteria and milk oligosaccharides. Trends in Microbiology 18: 298-307. https://doi.org/10.1016/j.tim.2010.03.008

Seth, E.C. and Taga, M.E., 2014. Nutrient cross-feeding in the microbial world. Frontiers in Microbiology 5: 350. https://doi.org/10.3389/ fmicb.2014.00350

Sheridan, P.O., Martin, J.C., Lawley, T.D., Browne, H.P., Harris, H.M., Bernalier-Donadille, A., Duncan, S.H., O’Toole, P.W., Scott, K.P. and Flint, H.J., 2016. Polysaccharide utilization loci and nutritional specialization in a dominant group of butyrate-producing human colonic Firmicutes. Microbial Genomes 2: e000043. https://doi. org/10.1099/mgen.0.000043

Sherman, M.P., Zaghouani, H. and Niklas, V., 2015. Gut microbiota, the immune system, and diet influence the neonatal gut-brain axis. Pediatric Research 77: 127-135. https://doi.org/10.1038/pr.2014.161 Smilowitz, J.T., Lebrilla, C.B., Mills, D.A., German, J.B. and Freeman, S.L., 2014. Breast milk oligosaccharides: structure-function relationships in the neonate. Annual Review of Nutrition. https:// doi.org/10.1146/annurev-nutr-071813-105721

Stahl, B., Thurl, S., Zeng, J.R., Karas, M., Hillenkamp, F., Steup, M. and Sawatzki, G., 1994. Oligosaccharides from human-milk as revealed by matrix-assisted laser-desorption ionization mass-spectrometry. Analytical Biochemistry 223: 218-226. https://doi.org/10.1006/ abio.1994.1577

Stokholm, J., Blaser, M.J., Thorsen, J., Rasmussen, M.A., Waage, J., Vinding, R.K., Schoos, A.M., Kunoe, A., Fink, N.R., Chawes, B.L., Bonnelykke, K., Brejnrod, A.D., Mortensen, M.S., AlSoud, W.A., Sorensen, S.J. and Bisgaard, H., 2018. Maturation of the gut microbiome and risk of asthma in childhood. Nature Communications 9: 141. https://doi.org/10.1038/s41467-01702573-2 
Tannock, G.W., Lee, P.S., Wong, K.H. and Lawley, B., 2016. Why don't all infants have bifidobacteria in their stool? Frontiers in Microbiology 7: 834. https://doi.org/10.3389/Fmicb.2016.00834

Thompson, A.L., 2012. Developmental origins of obesity: early feeding environments, infant growth, and the intestinal microbiome. American Journal of Human Biology 24: 350-360. https://doi. org/10.1002/ajhb.22254

Underwood, M.A., German, J.B., Lebrilla, C.B. and Mills, D.A., 2014. Bifidobacterium longum subspecies infantis: champion colonizer of the infant gut. Pediatric Research 77: 229-235. https://doi. org/10.1038/pr.2014.156

Van Limpt, C., Crienen, A., Vriesema, A. and Knol, J., 2004. Effect of colonic short chain fatty acids, lactate and $\mathrm{pH}$ on the growth of common gut pathogens. Pediatric Research 56: 487-487. https:// doi.org/10.1203/00006450-200409000-00157

Varki, A., Cummings, R.D., Aebi, M., Packer, N.H., Seeberger, P.H., Esko, J.D., Stanley, P., Hart, G., Darvill, A., Kinoshita, T., Prestegard, J.J., Schnaar, R.L., Freeze, H.H., Marth, J.D., Bertozzi, C.R., Etzler, M.E., Frank, M., Vliegenthart, J.F., Lutteke, T., Perez, S., Bolton, E., Rudd, P., Paulson, J., Kanehisa, M., Toukach, P., Aoki-Kinoshita, K.F., Dell, A., Narimatsu, H., York, W., Taniguchi, N. and Kornfeld, S., 2015. Symbol nomenclature for graphical representations of glycans. Glycobiology 25: 1323-1324. https://doi.org/10.1093/glycob/cwv091

Veiga, P., Gallini, C.A., Beal, C., Michaud, M., Delaney, M.L., DuBois, A., Khlebnikov, A., Van Hylckama Vlieg, J.E., Punit, S., Glickman, J.N., Onderdonk, A., Glimcher, L.H. and Garrett, W.S., 2010. Bifidobacterium animalis subsp. lactis fermented milk product reduces inflammation by altering a niche for colitogenic microbes. Proceedings of the National Academy of Sciences of the USA 107: 18132-18137. https://doi.org/10.1073/pnas.1011737107
Venema, K., 2012. Intestinal fermentation of lactose and prebiotic lactose derivatives, including human milk oligosaccharides. International Dairy Journal 22: 123-140. https://doi.org/10.1016/j. idairyj.2011.10.011

Walker, A.W., Duncan, S.H., Leitch, E.C.M., Child, M.W. and Flint, H.J., 2005. $\mathrm{pH}$ and peptide supply can radically alter bacterial populations and short-chain fatty acid ratios within microbial communities from the human colon. Applied and Environmental Microbiology 71: 3692-3700. https://doi.org/10.1128/Aem.71.7.3692-3700.2005

Wopereis, H., Sim, K., Shaw, A., Warner, J.O., Knol, J. and Kroll, S., 2017. Intestinal microbiota in infants at high-risk for allergy: effects of prebiotics and role in eczema development. Journal of Allergy and Clinical Immunology 141: 1334-1342. https://doi.org/10.1016/j. jaci.2017.05.054

Yatsunenko, T., Rey, F.E., Manary, M.J., Trehan, I., Dominguez-Bello, M.G., Contreras, M., Magris, M., Hidalgo, G., Baldassano, R.N., Anokhin, A.P., Heath, A.C., Warner, B., Reeder, J., Kuczynski, J., Caporaso, J.G., Lozupone, C.A., Lauber, C., Clemente, J.C., Knights, D., Knight, R. and Gordon, J.I., 2012. Human gut microbiome viewed across age and geography. Nature 486: 222-227. https:// doi.org/10.1038/nature11053

Yin, Y., Mao, X., Yang, J., Chen, X., Mao, F. and Xu, Y., 2012. dbCAN: a web resource for automated carbohydrate-active enzyme annotation. Nucleic Acids Research 40: W445-451. https://doi.org/10.1093/ nar/gks479

Zivkovic, A.M., German, J.B., Lebrilla, C.B. and Mills, D.A., 2011. Human milk glycobiome and its impact on the infant gastrointestinal microbiota. Proceedings of the National Academy of Sciences of the USA 108 Suppl. 1: 4653-4658. https://doi.org/10.1073/ pnas. 1000083107 
